
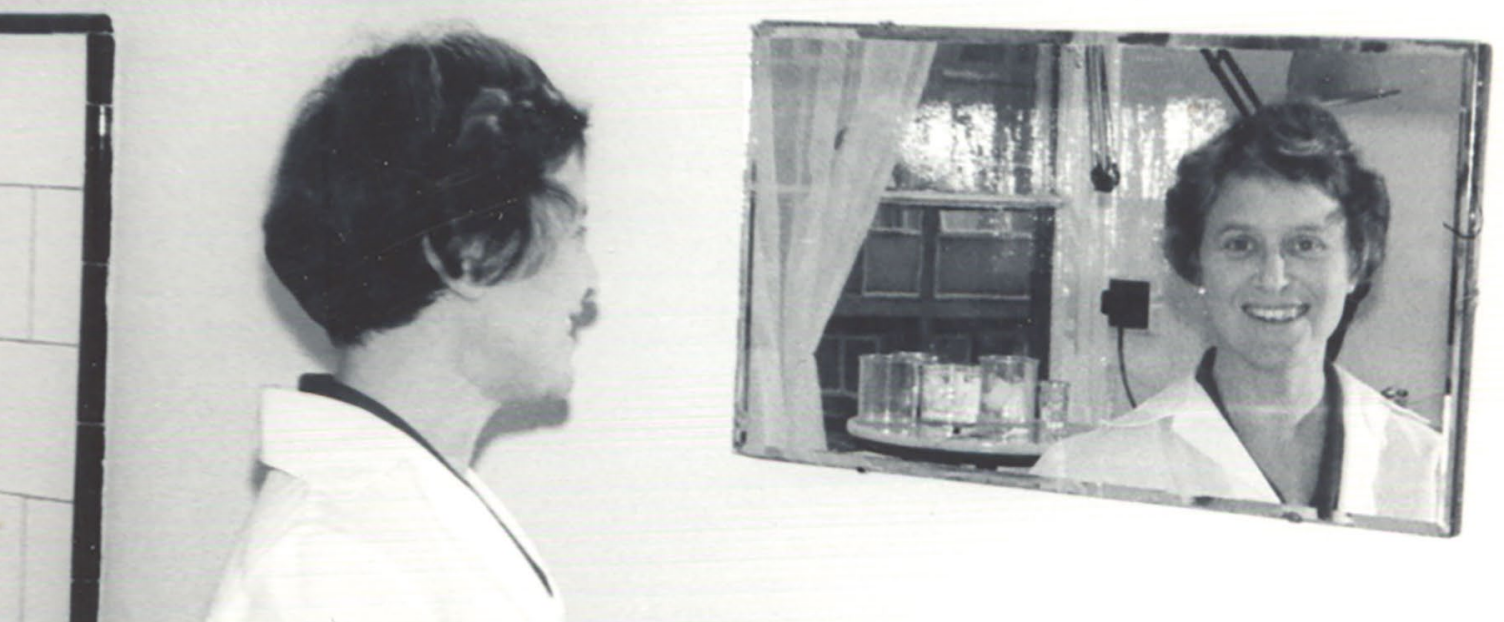

\title{
1. The importance of surgery assistance and maintenance: a plea for the employment of the trained dental nurse
}

\section{By M. M. Loretz, LDS ENG}

\section{Introduction}

The problem of surgery assistance and maintenance appears to me to be one of fundamental importance to the welfare of the dental profession. Its solution may not be a panacea for all our ills, but it certainly is for the majority of them. In attempting to justify this sweeping statement, I propose to consider the profession as a sick man, seek the cause of his sickness and outline the cure.

\section{Article information}

This archive article was published in the British Dental Journal in 1943 in Volume 75, pages 34-38. With thanks to Helen Nield at the BDA Library.
It seems to be generally agreed that all is not well with our profession; it is restless and dissatisfied, work is hard, rewards and recognition are meagre. There are factors influencing this condition which lie outside our control, but as they operate in America and on the Continent, where nevertheless the status of the dental surgeon is higher than it is here, it would seem that our sickness is of internal origin.

In considering the causes which appear to originate in a patient's own system, it is often helpful to view the position in the light of fundamental principles. Many diseases of the body can be traced directly to ignorance or neglect of fundamental laws, eg lack of rest, nourishment, or exercise. And so with institutions. In thinking the matter over from this angle, it appears to me that three fundamental principles have been ignored or side-tracked in the organisation of our professional life; one metaphysical and two physical. I mention the physical first because they are more familiar, but I consider that a proper appreciation and full practical expression of the metaphysical one would embody the other two. The first is - 'the necessity of the collaboration of the sexes'. Men and women are complementary. All the best works in the natural and social order are produced by collaboration between them. The second principle which we have tried to side-track is - 'the part is not equal to the whole', or, to put it more specifically, when a work requires by its fundamental nature two partners, it cannot be done by one alone. The all-embracing metaphysical principle, propounded by one of the greatest of human minds, Thomas Aquinas, may be expressed like this: there is in every man, firstly his own individuality, secondly the achievements or works of that individuality, and thirdly the 
feeling - love, respect - of his individuality for his work, or better, for the possibilities of that work. The third component of a whole man can be expressed more specifically as professional pride, or dignity. Professional dignity is not a form of conceit. Conceit is centred in, and is satisfied with, what has been achieved, and products a stultifying smugness; whereas professional dignity is centred on what could be achieved, and results in a humility which is ever producing, because it is ever striving and aiming higher, regardless of reward.

I believe that our profession is a sick man because he is only two-thirds a man, because the most vital and sustaining part of him, his professional pride, dignity, sense of vocation, is under-developed or poisoned or destroyed. The trouble starts in the earliest days of his studenthood, and attacks him through two channels, through his theoretical and his practical work. It is with the latter that I am concerned, but I must indicate one aspect of the former. It is the suggestion that the student 'would do better' to take the double qualification. The poison lies in how he would do better. As the curriculum is at present constituted, there is no case whatever for the contention that the extra subjects to be studied will improve the student's technique in dealing with the oral tissues. On the contrary, the ultimate reason, which may or may not be admitted, is that by taking the double qualification, one is enabled, not to do better, but ultimately to do no dentistry. Could anything be better calculated to depress and embitter a man's gradually awakening sense of vocation? But it is through the practical work that the attack is the more deadly, for our sick man is exposed to it daily and for life. In comparing the training of the medical and dental student, it will be noted that although their instruction in academic and basic subjects is similar and often taken together, in the practical application of these principles, notably those of surgical procedure, their careers are very different. The medical student, when he begins his work in the wards, has no chance of neglecting to apply these theories, his every movement is watched either by a critical 'pro', or an impatient or sometimes helpful staff nurse, or an exacting Sister. Later he will do duties in the theatre. There again he finds himself reminded, assisted, trained, disciplined, by the Theatre Sister and her staff. On the other hand, there is, notably in the conservation rooms of most teaching schools, an almost complete neglect to provide the dental student with the tuition, the means, or the assistance, for the logical and practical application of

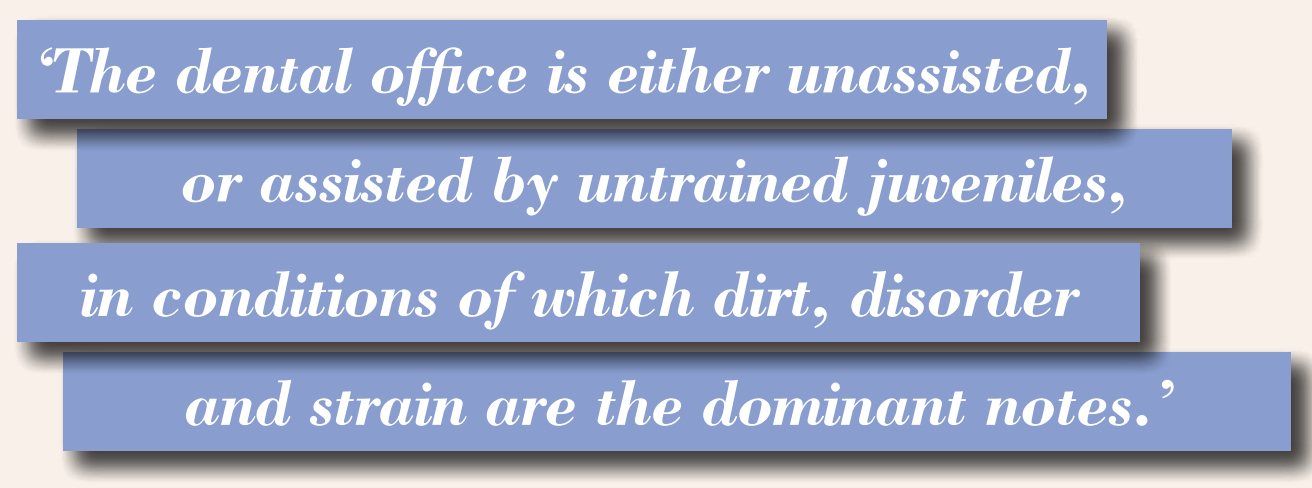

the principles of asepsis, anti-sepsis, or even common hygiene. This neglect I believe to be the fons et origo of our professional ills. It results in an ignorance and apathy which are completely soul destroying. It results in the acceptance in the public services of conditions which would not be tolerated at any price by trades or professions whose work demands far less intellectual or physical effort than ours in training or practice.

\section{The dental nurse in public service} A comparison of conditions under which medical and dental officers work in the public health services tells the same story and points to the same moral. The medical officer, for example, in his antenatal and immunisation clinics, is assisted by wellqualified, responsible nurses, so that he can do his work, and his work only, in conditions of which cleanliness, harmony and dignity are the dominant notes. The dental office, doing work involving far greater nervous and physical effort, is either unassisted, or assisted by untrained juveniles, in conditions of which dirt, disorder and strain are the dominant notes. How true this is may be seen in the following word picture.

A car stops outside a small country school. Two figures emerge. They are the dental officer and the dental attendant. Between them they transport large bulky packages from the car into the building. Those who have seen the MOI film on diphtheria immunisation will remember the shot of the doctor's arrival at the centre and be struck by the contrast. How the nurse was at the door to receive him, how everything was ready and arranged so that he could do his work, and only his work (simple subcutaneous injections) quickly, smoothly, and under all the conditions necessary for proper surgical procedure. But let us return to our dental officer. He is engaged with the attendant in arranging the temporary surgery. The collection of chipped and battered enamelware and worn instruments which emerge from their wrappings are more suggestive of a tinker's stall and, judging from the way she is handling them, they rank about that high in the attendant's estimation. We notice that she has bright red finger nails and a facial make-up which would grace any teashop or beauty parlour. Soon everything is in its place. The dental surgeon seems satisfied (just as a highly civilised boy scout feels when he has succeeded in cooking food by a fire built by his own hands and kindled by two flints), but he is not at rest. He has to supervise the activities of his assistant. She does her best, he will tell you, and seems keen, but he hasn't the time or energy left to train her as he would wish. She was appointed straight from an office. She offered herself for the post because she had always wanted to see how teeth were extracted. She soon learned the mix cements, of course, but she didn't know the first thing about asepsis, and hasn't the hang of it yet. He feels safer seeing to the syringe and needles himself, he does a lot of 'regionals'. But in actual practice she has little time to help him, as much as she could, because she has to do much clerical work. We commiserate. Oh well, he tells us, she is better than no one. Once when she was on sick leave he had to manage alone. Everything took much longer; there seemed hardly time for pure treatment; and the sessions were much more tiring; it really was grim. And on that note we leave him. But just consider for a moment what expressions of dismay, anger and disgust culminating in refusal would greet a suggestion that the medical officer of an antenatal clinic, in the absence through illness of the assisting health visitors, should himself prepare the examination room for his work and clear it up afterwards, and as a favour be given the services of a woman clerk (who volunteered because she liked chemistry at school) to help him test the specimens. This seems to be to be the nadir of our professional degradation - that in normal working hours, in normal times, and in normal circumstances (for absence through sickness is a normal occurrence) we should be allowed, or even expected, and sometimes 


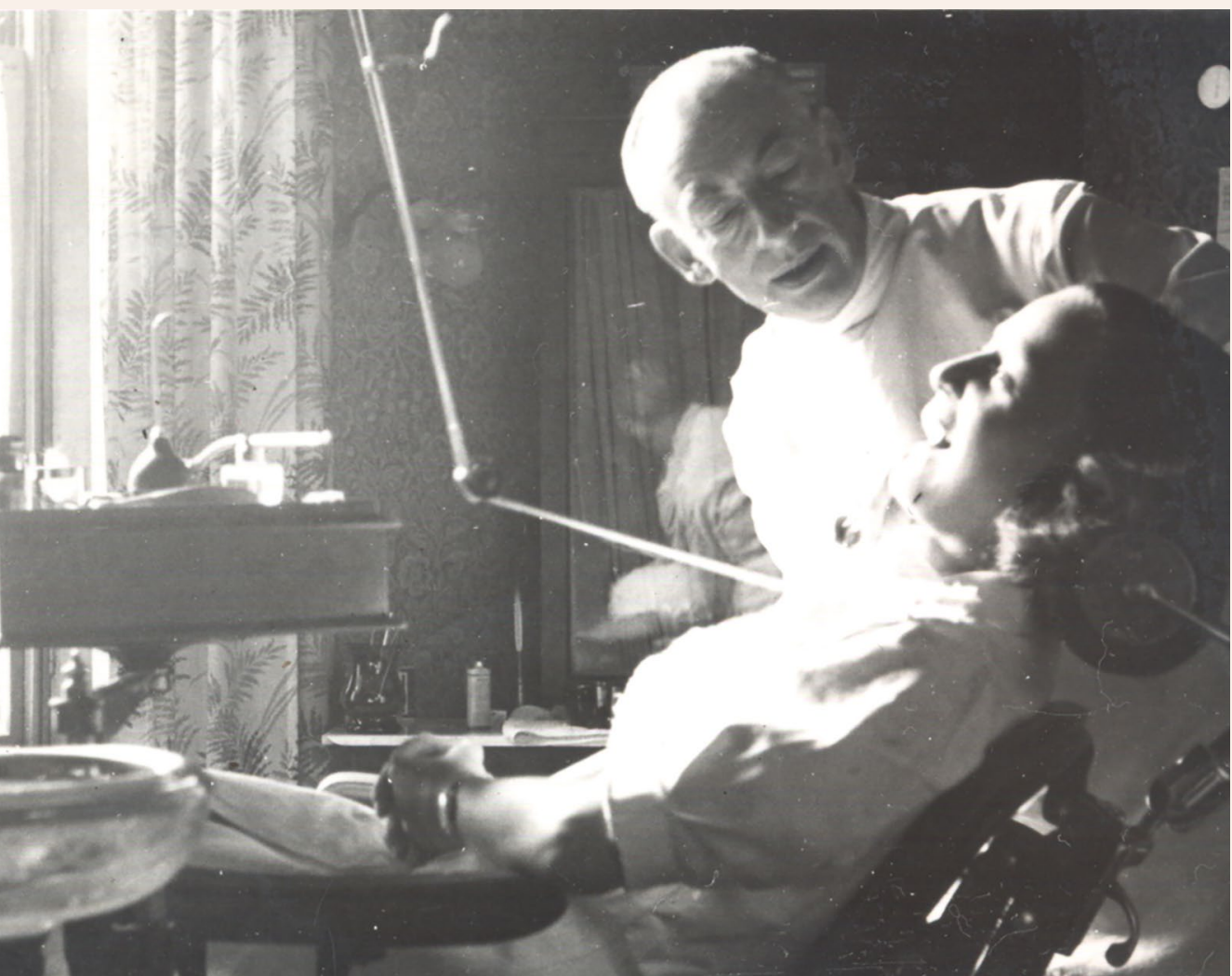

'The standards of working conditions

\section{are dictated by the dignity and efficiency}

\section{of our work and these conditions in their}

\section{turn demand the specially trained nurse}

ordered by a medical officer, to do highly skilled, delicate operations, on what may be called a sliding band of patients, unassisted and in conjunction with the work of nurse, clerk and porter.

It is undoubtedly a most shocking thing, that educated, highly skilled men and women, doing work of utmost social importance, should be subjected to conditions which hinder and belittle that work; conditions which, compared with those of medical colleagues and of public dental officers on the Continent, are grossly offensive to, if not wholly destructive of, their professional life. But the paralysing feature of the whole trouble is the fact that this state of affairs is largely of our own making, that our sick man is resigned to his illness, is blind to its origin and onset and appears to view any attempt at prevention and treatment with apathy and even resentment.

I would not attempt to saddle any individual or group with the responsibility for present conditions, but I would point out some of the milestones as they appear to me on our downward path. One was the arrangement which excluded a sufficient number of suitably trained nurses from the treatment rooms of dental hospitals. Another was the omission to make any provision for training such women. A third was the decision to scatter cheap and shabby treatment centres in the most sordid haunts of London, ignoring all the lessons of continental models previously studied. (Here I want to make myself quite clear. It is a fact that as regards standard of work and distribution, the public dental service in this country is second to none in the world. Where we lag behind, for instance, Norway, Sweden, Germany and Austria, is in the conditions under which the service is given. Surely we should lead in this field too.) The last milestone was the decision to withdraw trained nurses from the public dental service, on the admissible grounds of economy, combined with the complete neglect to provide (or give any reason for providing) adequately and specially trained substitutes. The cure lies in the hands of the older members of the profession, especially those responsible for education, and the senior dental officers. They must themselves recognise, and then make others know, the fundamental principles on which the cure is based - namely, that professional dignity is vital to professional life, that good working conditions foster it, bad ones destroy it; that the work of dental surgery, like general surgery, is one of dual activity, operational and maintenance; and that that of maintenance must be done by women specially trained by the nursing profession. Those in authority must be urged to institute schools for dental nurses in conjunction with the dental schools and the Royal College of Nursing so that the dental student may know and appreciate the importance of these nurses' work. Then, and then only, would the Board of Education or Ministry of Health be able to insist usefully on their employment in the public services.

The dental nurse's work and training There are three points in the outline of the cure which need further explanation. Firstly, 'dual activity'. This does not imply any regimentation of the operator by the nurse. The standards of working conditions are dictated by the dignity and efficiency of our work and these conditions in their turn demand the specially trained nurse. Thus the profession demands the conditions, and the conditions the nurse.

Secondly, these nurses' work. There is no question whatever of these women doing any work in the mouth. That is and must remain the province of the dental surgeon. Nothing he may have to do within it is beneath his dignity, and everything he does unnecessarily outside is. The lips are the gateway to our profession. There must be no gatecrashing. But the profession may rest assured, the dental nurses it needs and whom I have in mind, will be trained in duties so numerous and absorbing that they will have as little time and inclination for the dental surgeon's work as the theatre sister has for the surgeon's, or the surgeon for the anaesthetist's. Some of the duties of these women should be:

In Relation to Treatment - (a) Responsibility for the maintenance of treatment centres in the public dental service. (Analogous to Ward Sister or Sister-in-Charge of a department.)

(b) Chairside assistance. (c) Orthodontic and X-ray assistance. 
The ideals and principles of dental \begin{tabular}{l} 
mursing can best be inculcated by the \\
nursing profession. The practical \\
\hline application of these ideals and principles
\end{tabular}

must be taught by the nursing profession
In Relation to Education. - The teaching of oral hygiene by means of lectures in schools and social centres, and by demonstrations and toothbrush drill in nursery and infant schools and infant welfare centres.

Thirdly, training by the nursing profession. Our own long and bitter struggle against quackery should enlist our sympathy with the nursing profession which is now fighting that same battle, and we must be very careful to avoid any steps which would increase their difficulties. The dental profession should be the last to encourage quack nurses. The type of nurses we require can be produced only by (1) a basic training by the nursing profession, and (2) special training in dental surgery assistance and maintenance, given by dental surgeons themselves cognisant of the importance and nature of the standards required.

This training must therefore be a matter of the closest cooperation between the nursing and dental professions. The right attitude of mind towards one's work is of paramount and basic importance. Neither in theory nor in practice does it seem reasonable, nor indeed possible, for one profession to train a student in the ethics and ideals - the right attitude of mind - of another profession. The ideals and principles of dental nursing can best be inculcated by the nursing profession. The practical application of these ideals and principles must be taught by the nursing profession. A scheme for the reconstruction of the nursing profession is now being seriously considered, and it seems probable that something like it will one day be made statutory in order to close the nursing profession. It is as vital to the interests of the dental surgeons as it is to the women themselves, that dental nurses, as the auxiliaries of the service dealing with the most insidious and widespread of all diseases, should be within the fold. If this can be done only by means of a training in which the scales are somewhat overweighted on the side of the basic general nursing training, that will be the price which will have to be paid for the guaranteed material welfare of these women, which would then be of a standard which it would be very difficult for us to better or even equal if our profession was entirely responsible for them. This standard includes membership of a closed profession, a subsidised training, legal status and title, fixed minimum salaries, pensions, and prospects of advancement or change within their own profession. From the economic point of view the longer training is not as hard on the girls as it appears at first sight, because they can start young and presumably will be kept and clothed during most of their training.

Our first task would appear to be to effect a change of heart in certain members of the nursing and medical, as well as our own professions, who think, either that all the knowledge and ability required can be picked up in a few weeks by a young person straight from school or an office with the help of a few hints dropped from time to time by an overworked dental officer in the course of the day's work, or that a nurse with an ordinary hospital training is more than able to undertake the work without any specialised instruction. The efficiency of the latter is not commensurate with their cost; on the other hand, the monetary economy of employing the former does not compensate for their lack of general responsibility and professional dignity which in its turn has such a disastrous effect upon the dignity and efficiency of our work.

The women we require are, of course, not available at this moment - but neither are we ready for them. But after the war there will be a great number of women at present acting as dental attendants in the Forces, or reserved in the public dental service, or in private practices, who will want to continue the same kind of work. With perhaps many notable exceptions, they fall very far short of the standard I have tried to show we require and if let loose on the

\section{About the author}

Miss Margherita Maria Loretz was a devout Roman Catholic who wished to become a nun, but when her father died early, she became a dental surgeon to help with the family economy. After qualifying in 1920 and being appointed House Surgeon and Demonstrator in Dental Surgery - a rare distinction for a woman at that date - she entered the School Dental Service at the Chiswick clinic. The conditions in the School Dental Service at that time were poor, and Miss Loretz made it her life's work to improve the clinic and working conditions.

Miss Loretz's lectures to chairside assistants made a deep impression, as did her endeavours to encourage them to form a society. After her mother's death, being in very poor health, she was welcomed as a guest at St Mary's Convent, Ascot, where she superintended the dental treatment of the nuns. There she spent the last three years of her life, dying in 1953.

profession they will certainly perpetuate, and possibly aggravate, the conditions we are trying to suppress. We must plan to deal with all this wisely and sympathetically, so that the best of them may have the incentive and the means to become all we wish and need them to be - the perfect dental nurse.

\section{About the illustrations}

The photographs in this article depict Barbara Huntley who was a dental nurse in the early days of the NHS with dentist Dr Atkinson (around 1949-1950).

Barbara worked as a dental nurse from 1945-1998.

Photos shown with kind permission of Barbara Huntley and the John McLean oral history archive. Copyright BDA Museum.

Editor's note: we believe Barbara is posing as a dental patient in the second photo. 